\section{Accidentally swallowed toothbrush in mentally healthy patient: A case report and review of literature}

\author{
Usman M. Bello, ${ }^{1}$ Mamuda Atiku ${ }^{2}$ \\ ${ }^{1}$ Department of surgery, Bayero \\ University Kano, Kano; ${ }^{2}$ Department of \\ AnaesthesiaBayero University Kano, \\ Kano, Nigeria
}

\begin{abstract}
Most ingested foreign bodies are usually passed through the gastrointestinal tract. Ingested toothbrush however is almost never passed due to their long length, which doesn't negotiate the C-loop of the duodenum. Early endoscopic removal is however recommended to reduce chances of morbidity and mortality. Surgical option is considered when there is failure of endoscopic retrieval or when complication such as duodenal perforation has set in. In this case we present a 40-years-old man who accidentally ingested toothbrush that was removed surgically through mini laparotomy and gastrostomy.
\end{abstract}

\section{Introduction}

Foreign body ingestion commonly occurs in children and this includes coins, buttons, batteries, safety pins etc. In adults foreign bodies are commonly swallowed accidentally during eating in which case 7080 percent passed the gastrointestinal tract. ${ }^{1}$ Toothbrush ingestion however is commonly seen in patients with background psychiatric disorder such as bulimia nervosa or schizophrenia. This is in attempt to induce vomiting through pharyngeal stimulation with objects such as toothbrush. ${ }^{1-3}$ However, there have been few reported cases of accidentally ingested toothbrush in individuals with intact mental status as in this patient. Ingested toothbrush rarely passed beyond the duodenum due the fact that the long length of the brush cannot negotiate the C- loop of the duodenum. In this case we present an accidentally swallowed toothbrush in a patient with intact mental status.

\section{Case Report}

A 40-years-old mechanic presented with 3 weeks history of recurrent epigastric pain that comes usually after feeding. No history of vomiting or haemetemesis and no change in bowel habit. He gave history of accidental ingestion of toothbrush 3 weeks before while in an attempt to brush posterior part of his tongue. No other significant systemic symptoms. He is not a known hypertensive or diabetic and no history of personality change prior to this.

He initially presented to gastroenterologist where upper GI endoscopy was done, which confirmed the presence of the toothbrush in the stomach with the brush head impacted at the pylorus (image could not be retrieved from the image capture device). Endoscopic removal was attempted with a forceps, however it was not successful.

On examination he was a young man, not pale, afebrile and not in painful or respiratory distress.

Abdominal examination revealed a palpable elongated hard epigastric swelling that was transversely oriented with no associated tenderness and the mass could not be moved. No other significant abdominal findings.

There were no significant findings in other systems review.

Diagnosis of impacted accidentally ingested toothbrush with failed endoscopic retrieval was made.

Psychiatric evaluation was ordered to rule out background schizophrenia or bulimia nervosa. He was found to be mentally fit and healthy.

He was counseled and booked for mini laparotomy with gastrotomy, which he had under a balanced anaesthesia. Intraoperatively the toothbrush was found to be impacted at the pylorus (Figure 1 and 2). It was removed with careful manipulation and the gastrotomy was closed in two layers. The abdomen was closed enmass and anaesthesia was reversed successfully without any critical incidence recorded throughout the surgery.

He was commenced on graded oral sips on second day post operatively. He did well and was discharged after 4 days of admission.

\section{Discussion}

Ingestion of toothbrush is not an infrequent occurrence in adult. A literature search has found 40 cases between 1988 to $2000 .^{2}$ The majority of the ingested tooth brushes are found impacted in the stomach or the first part of the duodenum due to their long length as it occurred in our patient. As a result, stomach or duodenal erosion, ulceration and rarely perforation have been
Correspondence:MamudaAtiku，Department of Anaesthesia, Bayero University Kano, PMB 3452 Kano, Kano state, Nigeria.

Tel.: +234.8099312542.

E-mail: dratiku1963@gmail.com.

Key words: Swallowed toothbrush; ingested toothbrush.

Conflict of interest: The authors declare no conflict of interest.

Availability of data and materials: All data underlying the findings are fully available.

Ethics approval and consent to participate: No ethical committee approval was required for this case report by the Department, because this article does not contain any studies with human participants or animals. Informed consent was obtained from the patient included in this study.

Consent for publication: The patient gave his written consent to use his personal data for the publication of this case report and any accompanying images.

Received for publication: 8 July 2019 .

Revision received: 18 October 2019.

Accepted for publication: 18 October 2019.

This work is licensed under a Creative Commons Attribution NonCommercial 4.0 License (CC BY-NC 4.0).

(C) Copyright: the Author(s), 2021

Licensee PAGEPress, Italy

Pyramid Journal of Medicine 2021; 4:58

doi:10.4081/pjm.2021.58

reported. In a very rare reported case, passage into the colon with concomitant colonic perforation has been reported. ${ }^{2,4}$

Diagnosis is easily made on the basis of history, examination, plain films and endoscopic findings.

Once diagnosis is made early endoscopic removal is recommended. American society for gastrointestinal endoscopy recommend early removal of any foreign body $>6$ $\mathrm{cm}$. This recommendation is based on findings that more than $80 \%$ of foreign bodies greater than $6 \mathrm{~cm}$ can be removed endoscopically within 48 hours as impaction into the pylorus has not occurred. ${ }^{1}$ In some patients however endoscopic retrieval may fail due to pyloric impaction or duodenal perforation. ${ }^{5}$ In our patient endoscopic retrieval was tried but we could not succeed due to pyloric impaction of the brush head and lack of appropriate grasping forceps. In such cases where endoscopic retrieval failed surgical option is considered. This is through laparoscopic or open gastrotomy. 5,6 


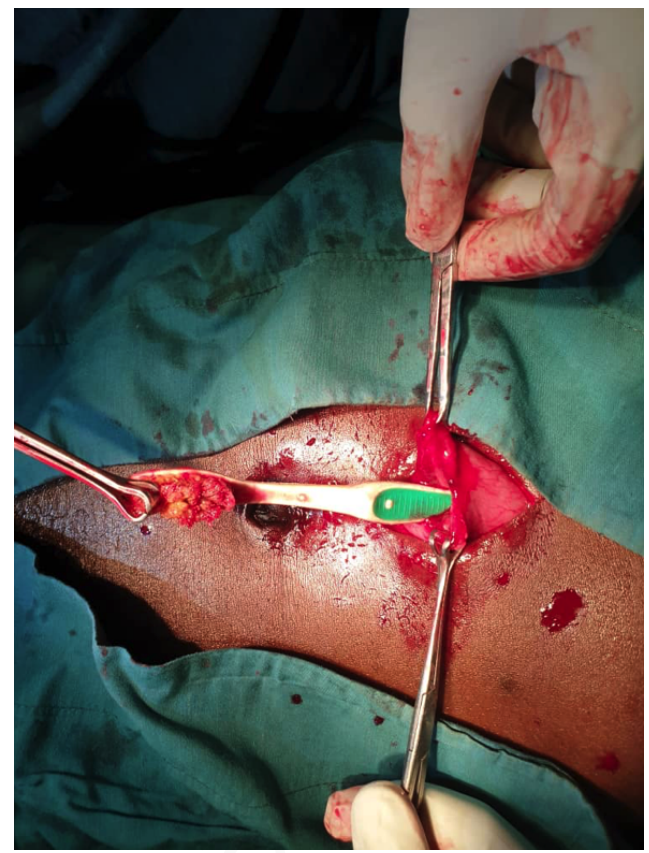

Figure 1. Removal of the toothbrush through gastrostomy.

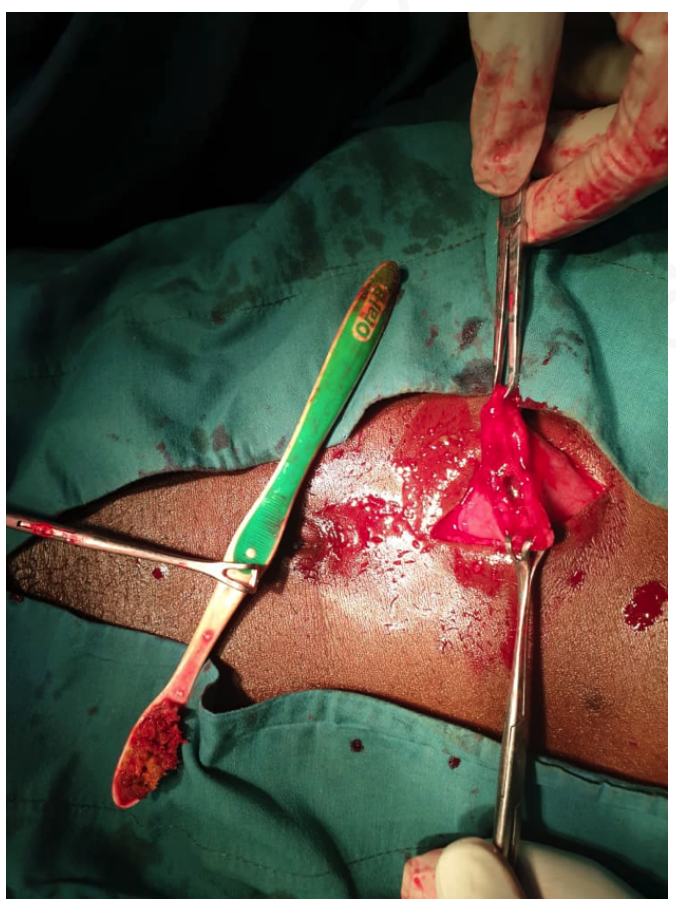

Figure 2. +Removal of the toothbrush through gastrostomy.
In our case we did open gastrotomy due to lack of laparoscopic facilities in the hospital.

\section{Conclusions}

Although toothbrush swallowing is seen in adults commonly with background psychiatric disorders, it does also occur in mentally fit patients as presented in our patient. Endoscopic removal remains the first intervention and surgery only considered when there is failure of endoscopic extraction or complications have developed.

\section{References}

1. Kiran S, Gupta D, Sadalage A, et al. Swallowed toothbrush: Case series. J Dig Endosc 2016;7:77-9.

2. $\mathrm{Kim} \mathrm{IH}, \mathrm{Kim} \mathrm{HC}$, Koh $\mathrm{KH}$, et al. Journey of a Swallowed Toothbrush to the Colon. Korean J Internal Med 2007;22:106-8.

3. Tonkic A, Bogdanovic Z, Grandić L. Successful Endoscopic Removal of a Swallowed Toothbrush: Case Report. Case Rep Gastroenterol 2011;5:122-4.

4. Chao HH, Chao TC. Perforation of the duodenum by ingested Toothbrush. World J Gastroenterol 2008;14:4410-2.

5. Gupta M, Gupta P, Gupta M. Extraction of swallowed toothbrush in stomach by pneumatic insufflation and gastrotomy under local anesthesia: A rare occurrence. J Res Med Sci 2014;19:472-3.

6. Wishner JD, Rogers AM. Laparoscopic removal of a swallowed toothbrush. Surg Endosc 1997;11:472-3. 